Frans B. Plötz

Marc van Heerde

Martin C. J. Kneyber

Dick G. Markhorst

\section{End-of-life decision \\ in a paediatric intensive care unit: decision making in light of the parents' religious beliefs}

\author{
Accepted: 15 March 2008 \\ Published online: 22 April 2008 \\ (C) The Author(s) 2008
}

Sir: Nowadays, the practice of withholding and withdrawal of lifesustaining treatments in children is medically and ethically acceptable when these measures can no longer yield a good outcome. In North America and Europe, 28-65\% of all paediatric intensive care unit (PICU) deaths follow a restriction in care [1]. However, clinicians' attitudes and actions regarding end-of-life decisions may be altered by exposure to a different culture or religion [2]. When clinicians believe that life-sustaining treatment is medically inappropriate or inhumane, they are not necessarily obliged to provide it simply because it is demanded on religious grounds by the parents. Instead, alternative religious interpretations and attempts to reach a consensus on the appropriate limits to life-sustaining treatment should be discussed [3].

A 7-year-old boy was diagnosed with a cerebellar medulloblastoma. Complete remission was initially achieved but 6 months before admission he had a relapse of the tumour without therapeutic options. He developed clinical signs of an upper airway obstruction. It was thought that a viral infection superimposed on his vocal cords paralysis was the main cause. Life-sustaining treatment was started because the viral infection was considered to be an intercurrent, curable event. He was intubated and assisted mechanical ventilation (MV) was initiated, after which he was transferred to our PICU. During the following days, his neurological condition rapidly deteriorated. No signs of pain or discomfort were observed.

The attending physician informed the parents about these developments. It became apparent that the prolongation of life-sustaining treatment would not contribute to a good outcome. Since death was imminent, the attending physician discussed the possibilities of withdrawing or withholding treatment with the parents. Withdrawing treatment, i. e. stopping MV, was not an option because of the parents' religious beliefs. For them, such action seemed to be intended to hasten death and was therefore prohibited. The attending physician was concerned that the parents would also object to withdrawal of MV after diagnosis of brain death. After careful consideration, the attending physician proposed to switch to PS/CPAP ventilation, thereby respecting the wishes of the parents to continue MV. In addition, the parents accepted the explanation that cessation of the central respiratory drive meant a fatal progression of the underlying disease, so that no change to controlled MV should be made. Shortly thereafter, the boy died in the presence of his parents and sister. He had experienced a fatal apnoea while still intubated and on PS/CPAP. Despite their tragic loss, the parents were pleased at their involvement in the discussion on the end-of-life decision and satisfied that their religious convictions had been respected.

There are no paediatric guidelines for withdrawal of a life-sustaining treatment like MV. The two approaches used are termed "terminal extubation", i. e. removing the endotracheal tube without weaning ventilatory support, and "terminal weaning", decreasing ventilator support before extubation [4]. This case report demonstrates that religious beliefs may prohibit both approaches and provides an elegant alternative in a patient with respiratory insufficiency of central origin.

Open Access. This article is distributed under the terms of the Creative Commons Attribution Noncommercial License which permits any noncommercial use, distribution, and reproduction in any medium, provided the original author(s) and source are credited.

\section{References}

1. Ten Berge J, de Gast-Bakker DAH, Plötz FB (2006) Circumstances surrounding dying in the paediatric intensive care unit. BMC Pediatrics 6:22

2. Sprung CL, Maia P, Bulow HH, Ricou B, Armaganidis A, Baras M, Wennberg E, Reinhart K, Cohen SL, Fries DR, Nakos G, Thijs LG, The Ethicus Study Group (2007) The importance of religious affiliation and culture on end-of-life decisions in European intensive care units. Intensive Care Med 33:1732-1739

3. Brett AS, Jersild P (2003) "Inappropriate" treatment near the end of life: conflict between religious convictions and clinical judgement. Arch Intern Med 163:1645-1649

4. Munson D (2007) Withdrawal of mechanical ventilation in pediatric and neonatal intensive care units. Pediatr Clin N Am 54:773-785

F. B. Plötz (浭) M. van Heerde · M. C. J. Kneyber · D. G. Markhorst

VU Medical Center, Department of Pediatric Intensive Care,

P.O. Box 7057, 1007 Amsterdam,

The Netherlands e-mail: fb.plotz@vumc.nl 